ENSAYO

\title{
La metástasis de la violencia o la salud cuestionada
}

\begin{abstract}
Eduardo Aristizábal
Psicoanalista, Bogotá, D.C., Colombia

Ensayo sobre el cruce de relaciones existente entre violencia y salud desde una perspectiva psicoanalítica, en el que se muestra porqué las condiciones de violencia, siendo estructurales, son el mayor obstáculo para lograr condiciones saludables de vida en la era de la ciencia. Se indica la importancia y la necesidad de contar con la palabra del sujeto y de las comunidades en toda política de salud que se quiera ejecutar, como quiera que esto es prerrequisito para la recuperación de las condiciones de salud. Esto sin perder de vista que las premisas que soportan tales políticas suelen ser ellas mismas cuestionables bajo el cuadro estructural de violencia que se describe.
\end{abstract}

Palabras clave: inconsciente, sujeto, ciencia, homogeneización, globalización, violencia estructural.

\section{Effects of violence metastasis on health quality}

The relationship between violence and health was examined from a psychoanalytical perspective, showing why the conditions of violence, being structural, become the main obstacle to healthy living conditions in the present scientific era. The importance and reliance on individual and community positive attitudes when implementing health strategies are shown, emphasizing that these attitudes are an essential requirement for the recovery of health conditions. This conclusion does not ignore the likelihood that the principles of health strategies are often themselves questionable within the structural framework of violence.

Key words: unconscious, subject, science, homogenization, globalization, structural violence.

El Centro de Investigaciones Económicas y Sociales de Gran Bretaña anunció recientemente su apoyo financiero a una investigación orientada a encontrar las causas genéticas por las que una persona se vuelve criminal (1). Diríamos, invirtiendo el orden de las palabras de su autor, lo siguiente: "instinto es destino porque el gen nos hace cuerpo" (2). Pues bien, bajo esta orientación, el sueño inveterado de controlar al ser humano avanza sobre toda desviación de la conducta hacia su normalización biológica. Para Jacques Lacan se trataba, por el contrario, de "irrealizar el crimen para humanizar al criminal" (3). Tal planteamiento lo hizo Lacan en 1950 con la convicción, en ese entonces, de que "ni el crimen ni el criminal son objetos que se pueden concebir fuera de su

\footnotetext{
Correspondencia:

Teléfono: 3107048

eduardoaristizabal@hotmail.com
}

Recibido: 18/07/02; aceptado: 18/09/02 referencia sociológica" (3). Significaba esto que la criminalidad se expresaba en un contexto de relaciones que era necesario ubicar para comprender la naturaleza psicológica del conflicto que motivaba la conducta. En los tiempos que corren, todo apunta a hacer creer que ya no estamos en eso. Queda por explicar, no obstante, porqué el aumento creciente de la criminalidad hoy día. ¿Será que el aumento de la criminalidad obedece a la mayor cantidad de nacidos portadores del gen de la criminalidad? Por supuesto que esta pregunta no está hecha para ser respondida porque es idiota y hacerla no quita nada de valor a las investigaciones que se anuncian, pero haberla hecho da a suponer que existe una relación entre criminalidad y modernidad en la que está por verse a qué aspecto de la modernidad habría que cargar el peso de este incremento. No sería descabellado pensar que la fuente del malestar moderno tenga que ver con el desconocimiento radical de la 
naturaleza del inconsciente y que la violencia hoy día sea una respuesta de los sujetos a la destrucción de su entorno simbólico operado por la ciencia y por la técnica. La globalización de la economía y la concomitante homogeneización de la cultura significan eso. Hay una poderosa razón psicoanalítica que explica porqué esta homogeneización conduce inevitablemente a la violencia ${ }^{1}$.

Se imponen dos interrogantes: 1) ¿por qué la fuente del malestar moderno tendría que ver con el desconocimiento que se tiene del inconsciente? 2) ¿Qué tiene que ver el inconsciente con la violencia? Veamos el segundo interrogante primero. Cuando se le habla a un bebé es como si se le latigara el cuerpo con palabras. Estas palabras lo marcan, dejan una huella en él. Si esta primera violencia no se ejerciera sobre un niño, ese niño sencillamente no hablaría. Ingresar al lenguaje es, pues, pasar por esta primera experiencia violenta de castración por la cual el cuerpo se eleva por encima del goce al que está entregado en su mismidad y entra a responder a los dictámenes del Otro. Esta violencia fundamental que las palabras ejercen sobre el cuerpo van a determinar, posteriormente, las vías significantes de realización de un sujeto en su deseo. El sujeto empieza a responder ahora por los dictámenes

1 La psicoanalista Colette Soler, en su texto La maldición sobre el sexo, explica porqué toda homogeneización de los discursos produce efectos de rechazo. Según esta psicoanalista, "desde el momento en que un discurso logra crear el 'todos iguales', crear un lenguaje común", crea la excepción. Esto significa que "toda forma de goce que difiere aparece como el Otro que ex-siste". Tal afirmación se deriva de las consecuencias que trae aparejada la diferencia sexuada. Así, "al generar el lenguaje el todo fálico, el goce de la mujer se impone como Otro, verdaderamente existente". Hay que hacer notar aquí que cuando Soler equipara el goce de la mujer a un goce Otro, éste es desconocido tanto para el hombre como para la mujer. "Pero -continúa la autora-, esta no es la única forma de hacer ex-sistir al Otro -y agrega: tal vez sea eso lo que a veces se pierde un poco de vista". "La mujer -dice- no es la única que encarna al Otro. Cualquier emergencia de pulsión que exceda las formas y los límites de un discurso dado hace surgir al Otro. Lo que quiere decir que cuanto más predomina la uniformización engendrada por el mercado mundial, mas consistencia toman los rechazos del Otro". Soler, Colette, La maldición sobre el sexo, Ediciones Manantial -Colección: Estudios de psicoanálisis, 2000 (4). del Otro. Por eso, Lacan afirma que el inconsciente es el discurso del Otro y que el sujeto, cuando desea, desea como Otro. Esta violencia del discurso es estructurante del sujeto y de su deseo. La respuesta al segundo interrogante es, pues, que el inconsciente es efecto de la violencia que el discurso ejerce sobre el cuerpo. Ahora sí abordemos la respuesta al primer interrogante.

La primera experiencia corporal de goce que deja la huella significante marca para siempre al sujeto cavando una enorme brecha entre lo que es su goce y lo que será su deseo. Entre la primera experiencia de goce que entrega el cuerpo al arbitrio de lo pulsional y el primer encuentro con el deseo que 'falicisa' el cuerpo, esto es, que pone al sujeto a girar en torno a la problemática del falo, puede un sujeto fijarse a una experiencia otra de goce que deviene traumática por estar en oposición al deseo. En adelante, tal experiencia representará para el sujeto su forma particular de resistirse a la ley del deseo en tanto que es la ley del Otro. Es por esto que los discursos homogeneizantes como el de la educación, que quieren introducir unos mismos deberes, unos mismos horarios, unas mismas normas, una igual disciplina a cuerpos distintos, son resistidos por el sujeto del goce. Este sujeto se resiste produciendo síntomas. La violencia es una de las formas que adopta el síntoma. Ya vimos cómo la homogeneización de la cultura llama a la violencia. ¿Cómo no va a ser causa de malestar el desconocimiento del inconsciente si ello significa desconocer radicalmente a un sujeto en su particularidad más esencial? Lo más radicalmente propio que tiene un sujeto es la manera particular que tiene de habitar su cuerpo. De esta suerte, el goce es suyo y la ley es de los otros.

Pero las cosas son un poco más complicadas porque bien pudiera decirse que en el inconsciente hay dos sujetos: uno que busca desear y otro que quiere gozar. El que busca desear ama al otro como el súbdito ama la ley. El que sólo quiere gozar es un desadaptado de esa ley. La combinación de estos dos sujetos en uno sólo producen un neurótico. El neurótico es aquel sujeto dividido entre lo que la ley le manda y lo que su goce le impone. Jalonado por la ley o por el goce, es alguien que se acomoda fácilmente a la realidad 
apoyado en sus fantasías. Cuando el fantasma se acerca demasiado a lo real empieza a producir síntomas. El síntoma en él es una transacción momentánea entre los mandatos de la ley y los imperativos del goce. El perverso, por su parte, es un sujeto que no está dividido por causa del goce, pero está escindido de sí por causa de la ley a la que requiere estar desmintiendo para mantenerse fuera de su órbita. El psicótico, fuera de la influencia de toda ley, goza. En términos generales y simplificados podemos decir que el sujeto del deseo inconsciente es el objeto mismo del psicoanálisis. Pero ya vimos que el sujeto del deseo inconsciente está trabado por el sujeto del goce. A partir de aquí las cosas no son tan simples.

La teoría que el psicoanálisis postula sobre el psiquismo no aligera la complicación. Veamos si podemos simplificar esta vez. Freud habló inicialmente de tres registros: el consciente, el preconsciente y el inconsciente. Después les varió de nombre y los llamó de otra manera: yo, ello y superyo. Debido a esta forma de nombrar esos registros, -hecha para poder leer, distinguiéndolas, las diversas manifestaciones del psiquismo-, el inconsciente en Freud parece como hundido en las profundidades de las capas sucesivas de la historia individual y colectiva, al punto que llevó a muchos a creer en la existencia de un inconsciente no sólo individual sino también colectivo. Para Lacan, en cambio, el inconsciente deja de ser lo profundo inmemorial de la ontogénesis del individuo o la filogénesis de la especie para pasar a ser lo que se manifiesta en el lenguaje. Es por ello transindividual y no pertenece a nadie en particular. El inconsciente está presente en los fallos del lenguaje que expresan el conflicto entre la ley y el goce en un individuo. Sin embargo, también para Lacan, el psiquismo está formado por tres registros: Io imaginario del cuerpo pulsional, lo simbólico del sentido que introduce la muerte en la vida y lo real de la vida que declina en el goce.

Lo imaginario se asienta con el predominio que adquiere la imagen especular en los primeros años de vida. La manera en que esta imagen especular afecta la imagen real del cuerpo es tal, que los celos mortíferos del yo en disputa con su imagen dan la medida de la agresividad sobre la que se volcará el sujeto con ocasión de un conflicto ulterior con su semejante. En efecto, ante el otro que le disputa el bien de su completud, este yo imaginario reaccionará siempre con violencia. Reaccionará en cambio con admiración si el yo ideal que lo condena a estar preso de la mirada del otro deja paso al ideal del yo que lo entrega al signo en el que cree reconocerse. Es aquí donde entra en función lo simbólico; pero lo simbólico denota la preexistencia del lenguaje respecto del ser que nace. Esta preexistencia anticipa la existencia de un sujeto, distinto de ese yo del dominio corporal, que es causado por la voluntad nominadora del Otro que lo nombra. El sujeto nombrado, cuando dispone de la palabra, habla, demandando del Otro su reconocimiento. Como sujeto de la demanda ansía reencontrar el lugar de inscripción que tuvo en el Otro, en la creencia de que ahí está lo esencial de su ser. Este sujeto ama el sentido como a sí mismo pero, cuando se ve enfrentado a lo real, pierde su ser. Un sujeto otro lo sustituye, aquél que confrontado con la diferencia de los sexos sabe de la muerte en el instante mismo en que descubre su deseo. Tenemos pues un 'yo' imaginario, sujeto de la agresividad, un 'yo' real, sujeto del deseo, y un 'yo' simbólico, sujeto de la demanda, que se debate entre el amor, el odio y la ignorancia. De este último sujeto emerge el individuo neurótico que se lleva bien con la realidad, pues logra instalarse en ella renegando de su deseo y no queriendo saber nada de él.

La realidad es aquéllo que sanciona lo prohibido cuando indica qué es aquéllo que está permitido. Esta distribución de las cosas llamada realidad oculta lo real de la red pulsional que atraviesa las relaciones establecidas en torno al objeto de goce. La realidad oculta sancionando porque es producto de esa articulación de lo simbólico con lo imaginario que da al objeto de goce la legalidad que requiere para que su circulación sea aceptada como bien de intercambio en cualquier sociedad, pues la realidad es la que crea esa ley de intercambio en lo social. Esto explica el sustrato de lo que es invariante en las sociedades a pesar de las diferencias culturales y los distintos modos de producción dominantes. Sin embargo, en el modo de producción capitalista es cuestionable 
la fundamentación de la realidad basada exclusivamente en el criterio antropológico de la invariancia pues, con la consolidación del sistema, surge la incidencia de otro factor que altera los fundamentos psicosociológicos utilizados para dar cuenta del modo en que cada quien enfrenta lo que cree que es la realidad ${ }^{2}$.

Ocultar sancionando es algo que se asemeja mucho a la noción de ideología de un filósofo como Louis Althousser. Pero la expresión 'ocultar sancionando' no se refiere sólo a la ideología. Si así fuera, la realidad quedaría equiparada a la noción estrecha de ideología que dice que un montón de sometidos han sido engañados por unos cuantos perversos iluminados. No hay tal. El sentido de la realidad es más complejo que esto. Por la época en que Marx produjo el concepto de plusvalía o 'más de valor', se creyó haber encontrado la razón concreta que explicaba la tendencia a la eternización del sometimiento de los hombres que vivían amarrados al ciclo repetitivo e infernal del capital. En consecuencia, se los llamó a hacer la revolución denunciando la ideología y los aparatos ideológicos del Estado que estaban hechos para ocultar la verdadera realidad, la realidad de la explotación sobre la que descansa el sistema de producción capitalista.

\footnotetext{
2 La ley de intercambio social es económica pero tiene su origen en la ley general de prohibición del incesto. Esto es lo que encuentra Levy Strauss al estudiar las estructuras elementales del parentesco en las sociedades primitivas y lo que resulta amenazado en las sociedades modernas capitalistas, particularmente con el capitalismo de la era científica. Es ya un hecho establecido que el principio de separación del objeto prohibido que funda la ley edípica es constitutivo del sentimiento de realidad en un niño. Pero este principio tiende a desaparecer con la caída del nombre del padre provocado por los adelantos científicos: la partenogénesis posible es su expresión más concreta. En términos generales, lo que se puede apreciar es que el sentimiento de realidad fundado por el principio de separación que une ley económica y ley social se diluye paulatinamente en las sociedades modernas. Los hallazgos científicos corroen las estructuras elementales del parentesco a la par que la producción de objetos catapulta las pulsiones e ilusiona regresivamente con la posibilidad de poder gozar del objeto prohibido, introduciendo así elementos psicotizantes en la sociedad inductores de violencia. Para el principio de invariancia, ver Levy Strauss, Las estructuras elementales del parentesco (5).
}

Lacan, al hacer intercambiable el concepto de 'más de valor' que entraña la noción misma de plusvalía con el concepto de 'más de goce' que halla en el psiquismo, opera un vuelco radical en la comprensión de la lógica del funcionamiento del sistema al hallar en el goce la causa primordial que mantiene a los individuos ligados más allá de las desventuradas estructuras socioeconómicas. Lo que mantiene incólume al sistema capitalista no es un engaño causado por una ideología, ni una plusvalía que garantiza el reciclamiento del capital, sino una técnica, alimentada por la ciencia, que ha hecho del objeto causa que mueve al sujeto, su propia economía. Para bien o para mal, y más para el goce que para el deseo. Este hecho es esencial para comprender los fenómenos de violencia que actualmente se suceden en el mundo, pues mucho tiene que ver la ciencia y la técnica en esa homogeneización del discurso que hoy domina y a la que ya hicimos alusión en un comienzo. De hecho, el avance acelerado de la técnica apoyada en la ciencia, al vaciar el lugar que tenía lo simbólico en el aseguramiento de la legalidad del objeto de goce en las sociedades reguladas por la tradición, entroniza lo real de la Cosa que llama a la muerte ${ }^{3}$.

Y bien, las cosas son así. La violencia en el mundo crece, la pulsión de muerte se enseñorea de las personas, la vida se degrada. Este estado de cosas inquieta y llama a la acción, especialmente cuando la población está siendo tomada por el terror, tal cual ocurre en países como el nuestro, atravesados por la insania de la guerra. El terror es un tipo de estrategia usado en la guerra para controlar sectores de población. Desde el psicoanálisis poco puede hacerse para enfrentar y transformar esta realidad, toda vez que

\footnotetext{
3 La Cosa es exterior al sujeto puesto que el sujeto es lo que un significante representa para otro significante según Lacan-, pero es interior al mismo puesto que le pertenece como lo ominoso de la vida, lo familiar extraño, lo que del cuerpo no es capturado por el significante. Por eso mismo es también lo que enuncia la ley de prohibición del incesto en tanto que refiere al real absoluto del goce: la total integración del cuerpo del niño al cuerpo de la madre. La ciencia 'entroniza lo real de la Cosa y llama a la muerte' porque desata el nudo normativo que ata el deseo a la ley". Lacan, Jacques: El seminario, libro 7, la ética del psicoanálisis, Ediciones Paidós, 1988, págs. 130 y 166 (6).
} 
es esencialmente una práctica de tipo individual cuyo tratamiento sólo surte efecto a partir de la queja de un sujeto ${ }^{4}$. Por fuera de lo que se hace dentro del espacio analítico, que incluye el diván y un sujeto de la palabra en camino de encontrar su puesto en el lugar del Otro, no es claro cómo hacer intervención psicoanalítica alguna. La razón es simple. El Otro como lugar no sólo designa en psicoanálisis el espacio que se recrea para facilitar la circulación significante, sino también la ocasión que se habilita para que se reproduzca el enganche pulsional de las palabras por las que el sujeto se ha mantenido atado a la voluntad del Otro.

El desprendimiento de la sujeción a la palabra del Otro pasa por el reconocimiento que hace el sujeto de esa parte de la pulsión que le pertenece, esto es, el reconocimiento de la cuota de goce que aporta al sufrimiento que le causa la relación de dependencia que tiene con el Otro. El individuo que está en análisis sabe, así, que hay un saber inconsciente que le habla pero no sabe cuál es su verdad. Muy pronto descubre, porque lo vive en carne propia, que la pulsión es la que sabe y el sujeto es el que goza. ¿Qué hacer con esta verdad psicoanalítica, más allá del espacio analítico en el que ésta se produce, si la relación con el saber también está tomada por las coordenadas del goce? Pendiendo de la mirada del Otro, atrapado en su voz, obsediado* por el objeto, cogido en su deseo, cuando cree ser vocero del propio decir, cae, inconsciente, en la red pulsional que hace de todos súbditos del Otro. No hay sujeto armado de ideales que no quede

\footnotetext{
${ }^{4}$ ¿Qué puede hacer el psicoanálisis en tiempos de guerra? Esta es una pregunta que ha estado abierta desde la época en que Freud fue solicitado para atender casos de neurosis traumáticas generadas durante la primera guerra mundial. Las neurosis de terror en población desplazada por causa de la violencia (masacres o desbordamientos naturales) demandan una atención interdisciplinaria en la que está por verse si el psicoanálisis puede intervenir y de qué manera puede hacerlo. El desarrollo de esta cuestión excede el planteamiento central de este artículo. La pregunta, pues, sigue abierta.
}

\footnotetext{
* palabra acuñada por el autor que comprime "obsesionado" (por el objeto) y "asediado" (por los objetos) y alude tanto a la situación psíquica de un individuo como a la dinámica social del mercado de objetos.
}

desarmado por esta lógica de la sujeción. ¿Cómo hacer jugar esta verdad en lo social sin entrar a ser parte de nuevo de la red de goce que a todos nos atrapa?

Esta es una de las razones de la imposibilidad de hacer intervenciones en lo social basados en criterios meramente ideales y no pragmáticos. Pero no es la única. Hay otras que enraizan en lo más íntimo de las personas y tienen que ver con el hecho de que quien sufre no quiere, necesariamente, ser sacado de su sufrimiento. La paradoja mayor con que nos encontramos en psicoanálisis es que el goce mantiene al sujeto en el sufrimento. En la cotidianidad, por ejemplo, hay distintas formas de sufrir que son otras tantas maneras de gozar: mantenerse en un trabajo a todas luces riesgoso para la salud o la vida; conservar una relación amorosa que en nada favorece el vivir juntos; mantener relaciones de amistad que son inconvenientes desde cualquier punto de vista que se las considere, etc. Argumentos habrá para justificar lo que se hace o lo que se tiene con un otro. Entretanto, la cauda silente del goce va haciendo su trabajo. Si está visto que el sujeto normal es el sujeto neurótico que se acomoda a las situaciones porque halla un lugar para él en la realidad, ¿qué es aquí la salud y qué es, entonces, la enfermedad? Un problema económico en el sentido más amplio de esta palabra. La salud es al bienestar y al placer lo que la violencia es al sufrimiento y al goce ${ }^{5}$. Entre la homeostasis del placer en la que tiende a mantenerse el deseo y el más allá del placer al que tira empujando el goce, la salud empieza a perderse a partir del quiebre del punto de equilibrio alcanzado por el sujeto en lo individual y por los

\footnotetext{
5 A propósito de esta relación, conviene precisar que la ética del psicoanálisis, "vinculada con la perseverancia en el ser, con el deseo en tanto camino al goce, con la confrontación sostenida a la falta, va en contra del bienestar y de las propuestas tranquilizadoras. Es en eso que el análisis no es una terapia sino la impugnación tácita de todas ellas" (....) El psicoanálisis "no apunta al principio del placer, al 'completo bienestar' de la definición 'mundial' de la salud, sino al más allá, a ese cuerpo que se experimenta aún en el sufrimiento y a través de una tensión sin pausa, al goce que, si sufre, es por los topes del placer." Braunstein, Nestor: Goce, Siglo XXI Editores, 1990, pág. 213 (7).
} 
individuos en lo social. Con respecto a las relaciones que se busca establecer entre violencia y salud, habría, pues, que empezar por reconocer cuál es la naturaleza de la violencia que desarregla el cuadro de la salud de un individuo, sujeto de unas relaciones marcadas por la violencia del Otro del discurso, o la de una población, compuesta por individuos sometidos por la violencia institucional orientada a garantizar, supuestamente, el buen funcionamiento de una sociedad. En términos de ley y orden, -en que no necesariamente acatar la ley o el deseo de mantener el orden es sinónimo de salud para una población-, lo que cuenta es la capacidad del Estado para mantener el control sobre todos los miembros de la sociedad. En asuntos pragmáticos, lo que cuenta es el poder y el poder no es otra cosa que el dominio del ejercicio de la violencia institucional requerida para mantenerlo. Factores de violencia son, entonces, todos aquéllos que alteran unas relaciones de poder estables, venidos de dentro o de fuera del centro mismo del poder. Hay factores internos a una nación que surgen de relaciones inequitativas generadas por grupos o sectores dominantes que se resisten a perder sus privilegios cuando las relaciones a su interior se alteran por motivos económicos o ideológicos. También los hay externos a un país, más sutiles y despersonalizados.

Hasta aquí hemos tratado de dar un cuadro lo más simple posible de las relaciones de los individuos con la violencia y la salud sin perder de vista la complejidad que implica establecer tales relaciones. Intentaré de nuevo retomar por otra vía para esclarecer lo que haya podido quedar oscuro y aclarar, a su vez, otras cuestiones que no hayan sido tratadas.

¿Por qué la guerra? Tal fue la pregunta que Einstein formuló a Freud, a instancias de la Liga de las Naciones, pasada la primera guerra mundial. Freud contestó a ella en una carta en la que se atreve a lanzar la hipótesis que deriva la violencia de la aplicación del principio de exclusión, esto es, de la aparición, en la historia, de la apropiación privada de los bienes comunales y el inevitable ejercicio concomitante del poder para garantizarla.
Sólo que Freud no dice que sea ésta la razón fundamental, pues las armas equiparan la fuerza y con ellas hay lugar a la aparición del derecho como aquéllo que ordena la sociedad en torno a una ley orientada a garantizar la convivencia social. Sin embargo, es sabido que esto no es suficiente. ¿Por qué la ley no es garantía del derecho, retornando por ello la violencia? La paz es precaria -dice Freud- porque siempre habrá quien quiera atravesar las fronteras que demarcan la ley, trasgrediéndolas a nombre de cualquier cosa, si bien aquéllo que motiva su conducta son las pulsiones que lo incitan a querer apropiarse del goce que no es suyo.

El encausamiento del individuo por la norma se logra, según Freud, reprimiendo sus pulsiones. Por esta causa el individuo entra en contradicción y en conflicto con sus semejantes. Es lo que Freud afirma cuando hace alusión a las causas del malestar en la cultura, indicando que si el hombre enfermaba era por causa de las exigencias culturales que pesaban sobre él. En efecto, haciendo eco a las palabras del filósofo Hegel, el hombre, decía, es un animal enfermo, desadaptado de sus "instintos".

Para el pensador colombiano Estanislao Zuleta, "el psicoanálisis desprovisto de una verdadera sociología científica y de una crítica histórica rigurosa, está continuamente amenazado por un naturalismo individualista que trata de interpretar todos los fenómenos de la vida social como irrupción o represión de los instintos" (8). Afirma Zuleta que "lo que más impresiona en esta torpe especulación (se refiere al ensayo de ¿Por qué la guerra? de Freud), es la incapacidad de comprender el carácter contradictorio y brutal de la civilización capitalista, en la que no ve más que la represión y la sublimación de los instintos más bajos, llegando incluso a considerar la guerra como una explosión pasional en la que los pueblos se levantan contra la coerción educativa de esa 'magna comunidad de intereses creada por el tráfico y la producción'. Es algo tan grotesco como si dijéramos que la naturaleza humana, dañada por el pecado original -el deseo incestuoso y el instinto de destrucción-, rompió las barreras morales con las que se trataba de mantenerlas 
en el camino del bien y se dejó llevar una vez más por las tentaciones de Satán" (8).

Convengamos, por ahora, que no es ésta exactamente la interpretación que habría que darle a lo formulado por Freud en ese texto y digamos, por lo pronto, que lo simbólico está para intervenir lo real de las pulsiones y encuadrar lo imaginario de los individuos, al conferir al sujeto que hay en cada uno de nosotros un lugar en la red social y en la cultura, y que este orden es el que hace posible que las diferencias causantes del conflicto entre los miembros de una sociedad (diferencias relativas al sexo, la edad, la propiedad o el saber) puedan ser tramitadas. Lo que se sabe a partir de Freud y de Lacan, principalmente de este último, es que la sociedad no logra someter del todo lo real pulsional en el individuo, ya que hay algo que insiste por fuera de toda normatividad simbólica y que se expresa como lo más singular que tiene el sujeto, particularidad ésta a la que podemos atribuir ser la causa de las más variadas conductas sintomáticas. A esta resistencia que el sujeto opone a la norma, Lacan la llama goce, concepto que hemos intentado establecer y esclarecer desde el inicio. Pero veamos: es en consideración a los caminos selectivos del goce que cualquier solución del conflicto se torna imposible. La realidad social será por ello siempre conflictiva, pues lo que está en la base del conflicto es la posición del sujeto respecto del goce. Lo que se puede apreciar en momentos de crisis es que, cuando esto sucede, cuando un conflicto estalla en el individuo o en la sociedad, el goce liberado por la violencia del conflicto empieza a deambular como ánima en pena buscando de nuevo hacer pareja con el cuerpo.

Pues bien, una de dos: o lo simbólico es garante de la estabilidad de la estructura psíquica y logra conservar a los individuos dentro del marco de una normalidad más o menos sobrellevada, por estar sostenida en un cierto grado de racionalidad compartida por todos, o no lo es. Si no lo es, ¿cómo impedir que lo imaginario retorne y haga presa del psiquismo empujando de nuevo hacia la confrontación paranoica, constitutiva de la más tierna infancia? Como dijera Rimbaud, el poeta: 'yo es el otro', pero un otro presente de una manera tan problemática y conflictiva en el individuo que la forma correcta de expresar esta verdad es: 'o yo o el otro', verdad ésta que está indicando un tipo de confrontación en la que el individuo está preso de la relación mortífera con la imagen del semejante. Algunas veces, peleas de pareja causadas por celos tienen esta raíz y, en ocasiones, estos celos son causa de inauditas tragedias que terminan en muerte. Cuando esto sucede decimos que algo falló, que algo dentro del psiquismo falló protuberantemente, que algo del orden de lo simbólico no hizo barrera al rapto homicida, algo relacionado con el padre prohibidor. Sin embargo, mientras en la sociedad perdure el equilibrio inestable conocido por nosotros como salud, los delincuentes, los psicóticos, los neuróticos antisociales y los pervertidos transgresores de la ley, así como los sujetos calificados de normales, estarán resguardados el uno del otro por las rejas de su síntoma o de su encierro material en espacios debidamente delimitados por la sociedad, pudiendo los más vivir sin ser estorbados en su cotidianidad. Lo que no es posible, por supuesto, es garantizar que esto suceda, así no más, durante el tiempo de fractura del orden simbólico en el que empieza a brotar, sin control, toda clase de violencia, amenazando con hundirnos de nuevo en la versión esquizoide y paranoica del mundo primario del que venimos, $y$ del que salimos, hacia el encuentro normativizado con los otros.

Si la prohibición, instalada ya en el psiquismo de las personas por el influjo de la familia, la iglesia - la escuela, deja de operar por causa del desorden social en un momento dado, la violencia emergente de las pulsiones amenaza sustraerlas a todo principio aglutinador en torno al cual estén organizadas. Los dirigentes que ven cómo los individuos quedan así expuestos a la virulencia de sus manifestaciones tanáticas pueden verse empujados a querer gozar también ellos, en nombre del orden, ejercitándose en la contraviolencia obligatoria para poder contenerla. Son éstas las situaciones en las que el imperativo de goce en los gobernantes se expresa en el llamado que les hace la dictadura, esa tentación de querer ejercer a toda costa un control represivo sobre todos los miembros de la sociedad. En estas circunstancias, el régimen que se instaura es un 
régimen contrario a todo nicho ecológico de salud, propiamente hablando.

"Si la salud es esto", -dijo una vez Aristóteles"tendrán necesariamente que ser hechas o existir ciertas cosas" (9). La frase la formula Aristóteles para destacar el carácter lógico de un argumento. Lo que se haga en salud tiene, pues, que estar en estrecha relación con la idea que nos hagamos de ella. En este sentido, el regreso a la normalidad (normalidad llevada al plano de la estandarización de las condiciones de vida que se consideran mínimas para garantizar la salud a toda la población), no sólo depende del aspecto de salud mental que se considere relevante, sino también, del aspecto de salud material que se crea suficiente. Estas dos condiciones se aúnan en el comportamiento saludable de un pueblo que acata las normas. En efecto, qué tan normal es una población está en estrecha relación con qué tan normalizada está su conducta y qué tan acorde es el comportamiento de los miembros con lo dispuesto por las reglas que se establecen para regular su convivencia. Pero si las normas de regulación de la vida económica, social y política han sido rotas por procesos externos que

6 Globalización significa movilidad extrema de la inversión. Que se pueda decidir en la bolsa, a la velocidad de las computadoras y las acciones, hacer una inversión en cualquier lugar del mundo, no es malo de por sí. Lo malo está en pretender que esa inversión se haga sin que existan muchas trabas legales en el país que la acoge. Estamos, pues, en un nivel de las relaciones comerciales entre estados dominadas por el capital privado internacional en las que los países pobres se hallan maniatados para reclamar responsabilidades sobre las consecuencias ecológicas o sociales que el capital multinacional propone. Estos países no pueden oponerse a las propuestas de inversión en las condiciones que se les proponen porque el país las necesita y tampoco tienen cómo oponerse a que se retiren de la noche a la mañana si encuentran otro país que les ofrece mejores condiciones de rentabilidad, sin importar la cantidad de obreros que quedan desempleados pues ese es un problema social que le compete resolver al Estado del país que abandonan y no a ellos. ¿A quién reclamar? ¿Contra quien protestar? $¿ A$ qué instancia dirigirse para que al menos indemnicen los desastres ecológicos causados, en ausencia de leyes mediadoras de la relación capital-trabajo? Todo esto es lo que angustia en el nuevo escenario de la globalización. Ver para esto: Indart, Juan Carlos: Sobre la globalización y sus malestares, en: La clínica de la no relación sexual, GELBO, 2000, págs. 164-165 (10). introducen otras reglas de juego -como sucede en estos tiempos de globalización- ${ }^{6}(10)$, la normalización que se quiera restablecer cuando el conflicto estalle, será perversa en sus fundamentos. Decimos perversa porque la idea de normalización que implica la aceptación de las reglas del gran capital tiene al goce del dinero como único referente de todo ideal que busca dejar por fuera, con sus demandas, a ese "Otro de deseo, responsable de las consecuencias de su deseo" (10). Es perversa, además, porque estas circunstancias objetivas de desmonte de toda responsabilidad hacen más difícil aún, en las personas individualmente consideradas, la asunción subjetiva de su propio deseo. Recordemos que el deseo en el individuo es el deseo del Otro. Al parecer, esto es lo que está detrás de la violencia que campea en varios países del mundo, a más del nuestro, en donde a la población le resulta imposible integrarse a los ciclos del gran capital y en los que la identidad de los miembros es violentada por la imposición de otras formas de identidad venidas de fuera que niegan las suyas en sus fundamentos raizales, tribales, familiares o nacionales.

Si "un batir de alas de mariposa en Pekín puede producir un ligero soplo que, poco a poco, acabe por dar origen a un huracán en California" 7 , ¿una movida de ficha en una bolsa lejana puede llegar a causar hasta una masacre en un retirado villorrio? ¿Es así de caótico el origen del orden económico mundial en la era de la globalización que puede llegar a ser catastrófico para tantos desventurados? Tal vez no es posible hacer tan tremenda comparación sin desvirtuar lo que quiso decir Prigoguin con su sentencia famosa sobre el caos. Pero es un hecho que la globalización ha profundizado el caos en el mundo del que hacemos parte. Este caos nos afecta más allá de lo que pensamos, con un agravante adicional para nosotros, que la inserción en la economía mundial la hemos hecho fundamentalmente vía el dinero del narcotráfico que corrompió todas las

\footnotetext{
Frase dicha por el premio nobel de química llya Prigoguin, según lo reseña Guy Sorman en: Los verdaderos pensadores de nuestro tiempo, Seix Barral, 2 ${ }^{\mathrm{a}}$. impresión, 1991, pág. 41 (11).
} 
instituciones. ¿Una masacre podría llegar a estar sustentada en causas tan sutiles como éstas, causas de las que nada podrán entender aquéllos que creen saber porqué la incitan o la promueven? Desconcertante y mortífera en sus efectos despiadados, pareciera ser tan sólo la manifestación cruel y enfermiza de una conducta alienada. Y, por supuesto, es un hecho que el deseo de masacrar, que bien puede estar presente como deseo en el inconsciente de todos, sólo se materializa a través de personas que no pueden sino estar tremendamente desquiciadas. Pero cuando estas prácticas parecen responder a estrategias de guerra promovidas por otros distintos de quienes son sus protagonistas, el desquiciado es el mundo que crea este tipo de seres y las autoridades que no impiden las masacres argumentando no tener cómo oponerse a ellas, tanto como el pueblo que las soporta pasivamente en su dolida inermidad, pues la manifestación de su impotencia es también expresión del desarreglo de la salud fundamental de un pueblo. ¿Cómo responder a esto? Por el psicoanálisis sabemos que no es conveniente ir más allá de lo simbólico sin disponer de una dialéctica de la 'incompletud' (sic) que contenga la furia de la violencia que se desata con su ausencia; que es imprudente, también, entregarse a ejercicios imaginarios de poder que solicitan con furia más violencia. De ahí que las tesis que llaman a armar a la población para enfrentar la inseguridad causada por la violencia sean inconvenientes y peligrosas porque permiten que se desboque el más de goce que la ley no puede contener por ella misma en tales circunstancias. Pero la dialéctica de la 'incompletud' sólo es posible ponerla en ejercicio, en tanto que dialéctica, mediante un psicoanálisis con un psicoanalista. Nada es más contrario al psicoanálisis que la aplicación de medidas represivas para contener la anarquía y violencia vividas por un sujeto. Mas nada de esto es posible plantearlo en el ámbito de la sociedad sin caer en la inocencia y la ingenuidad políticas.

Es cierto que ninguna sociedad en conflicto escapa a la tentación de la represión. En contextos de política de Estado, un proyecto de normalización se acompaña de estas medidas. Sin embargo, un verdadero proyecto de normalización debería incluir el rescate del sujeto de la anomia social en que se halla si uno de los alcances de tales medidas es abordar correctamente la problemática de salud pública que presenta un país en estas circunstancias. El marco posible de realizaciones factibles de un proyecto tal significaría devolverle la palabra a los miembros de las comunidades afectadas para que se exprese el sujeto que hay en cada uno de ellos. Este sería el proceder psicoanalítico adecuado en tales circunstancias. De hecho, se debería buscar que la antinomia responsabilidad versus culpabilidad no funcione sólo para los que toman las decisiones sino que incida también en aquéllos a quienes estas decisiones afectan. Esto es algo ya sabido por todos los promotores de salud comoquiera que tal planteamiento es parte esencial del éxito de toda campaña de atención primaria en salud.

Lo anterior se anota para indicar que en un país donde existe una guerra interna no declarada el peligro de que las fuerzas legítimas no actúen demarcando su accionar de cualquiera de los bandos en conflicto o que la conducta de algunos de los funcionarios del Estado se parcialice en aras de la simpatía que tengan por alguno de ellos, puede conducir a la confusión enfermiza de los fines. En estas condiciones, lo que resulta necesario deviene inconveniente si a alguno de los bandos en conflicto le da por juzgarlo inadecuado a los objetivos de la guerra. Es un hecho que buscar minimizar los efectos de la guerra sobre la salud mental o corporal demanda la aplicación de estrategias encaminadas a sustraer del terror a la población que se halla en medio del conflicto. Pero el contrapeso a esta iniciativa está justamente en el ambiente de 'paranoización' (sic) generalizada que se crea con estas conductas ambiguas. De suyo, la interpretación paranoica de los miembros de los bandos en conflicto va a pesar más que la consideración del bien social o del bien público que esté en juego. En este sentido, no es poco decir que el personal de salud arriesga su vida si quien domina el territorio por el que deben transitar piensa que "quien no está con él está contra él", como es lógico que se piense cuando es la lógica paranoica la que domina el escenario de las relaciones sociales. 


\section{Referencias}

1. Sección Educación. ¿Dónde nacen los criminales? E Tiempo 2002 mayo 26; p. 2-7.

2. Galende E. Psicoanálisis y salud mental - para una crítica de la razón psiquiátrica. Buenos Aires: Paidós; 1994. p.245 -8.

3. Lacan J. Escritos I. México: Siglo XXI Editores; 1984. p.118,121.

4. Soler C. La maldición sobre el sexo. Buenos Aires: Ediciones Manantial; 2000.

5. Strauss L. Las estructuras elementales del parentesco. Madrid: Editorial Planeta; 1993.
6. Lacan J. El seminario Libro 7, La ética del psicoanálisis. Buenos Aires: Paidós; 1988. p.130,166.

7. Braunstein N. Goce. México: Siglo XXI Editores; 1990. p.213.

8. Zuleta E. Ensayos sobre Marx. Medellín: Editorial Percepción; 1987. p. 224-5.

9. Aristóteles, Física. Madrid: Editorial Gredos; 1995. p.170.

10. Indart JC. Sobre la globalización y sus malestares, en: La clínica de la no relación sexual. Bogotá: Gelbo; 2000, p.164-5,169.

11. Sorman G. Los verdaderos pensadores de nuestro tiempo. Barcelona: Seix Barral; 1991. p.4. 